\title{
Development of Environmental Performance Model Using Design for Six Sigma (DFSS)
}

\author{
Pregiwati Pusporini, Kazem Abhary, and Lee Luong
}

\begin{abstract}
Due to the increasing demand for green manufacturing, environmental performance has become an important consideration during product design and development. The new paradigm of competitiveness of product would involve quality and environmental performance. This paradigm will force manufacturing industry to improve their environmental performance continuously. That means, environmental performance has to be considered during product design and development process. Moreover, environmental performance has to be put as a part of business activities in the manufacturing industry and also has to be targeted as the improvement effort. Current application of product development is concerned with four areas of performance like cost, quality, time and service. There is no consideration of environmental performance into continuous improvement methodology or product development. Environmental evaluation is considered quite late in the product development process and it is conducted separately (not integrated with development activities). This paper presents the development of environmental performance model using Design for Six Sigma (DFSS). The proposed model could be integrated into product development or continuous improvement methodology as the improvement target.
\end{abstract}

Index Terms-Green manufacturing, environmental performance, continuous improvement, design for six sigma.

\section{INTRODUCTION}

Designing and manufacture of eco-friendly (sustainable) products has become challenging for manufacturing industry and this concern is growing due to the pressure from the government regulations, stakeholders and public opinion. Tyteca [1] pointed out that there are five main factors for business environmental performance measurement namely, biosphere, financial stakeholders, non financial stakeholders, buyers and public. These pressures would force the company to improve their environmental performance continuously. Basically, the main concern of environmental performance measurement is to evaluate and measure the current environmental performance of any organization and then compare it with the target value by the organization managements. Moreover, environmental performance

Manuscript received November 4, 2012; revised January 10, 2013.

Pregiwati Pusporini is with the School of Advanced Manufacturing and Mechanical Engineering, University of South Australia, Australia and Lecturer at Department of Industrial Engineering, University of Muhammadiyah Gresik, East Java, Indonesia (e-mail: puspy001@mymail.unisa.edu.au).

Kazem Abhary is with the Sustainable Mech. And Manufacturing Design at School of Advanced Manufacturing and Mechanical Engineering, University of South Australia, Australia (e-mail: Kazem.Abhary@unisa.edu.au).

Lee Luong is with the Manufacturing Engineering at School of Advanced Manufacturing and Mechanical Engineering, University of South Australia, Australia (e-mail: Lee.Luong@unisa.edu.au). evaluation is to ensure that manufacturing activities would move toward a direction for sustainable product development, that means would be acceptable for the society and the environment. Jasch [2] pointed out that a strong commitment is required to put environmental performance as continuous improvement target for the current environmental management system like ISO 14001 and the ISO standard on environmental management system. It is important to put environmental performance as an improvement target for continuous improvement project.

Lean six sigma as a continuous improvement methodology has been conducted successfully for many industries. Commonly, the current application of this methodology at the manufacturing company focuses on traditional approach that would consider on four areas of performance i.e. quality, cost, time and service. Conventionally, the main concern for continuous improvement methodology like lean six sigma is how to improve the quality of product at low cost. Several studies of lean six sigma implementation will be presented below to show the most applied indicators. Aggogeri and Mazzola [3] showed that the combination of lean six sigma could increase the performance level of a manufacturing system in particular a significant result in reduction of costs of poor quality, increasing process cycle efficiency and also increasing process capability. Lee and Wei [4] mentioned that the combination of lean and six sigma concept at PCB manufacturing industry would recognise key process input variables which would result in reducing the variance of mold changing process and time. Dario et al [5] presented an application model of the lean six sigma DMAIC to improve manufacturing process that has a significant result in reducing costs saving on raw material. Kumar et al [6] showed that the implementation of lean six sigma methodology would have a dramatic improvement on defect per unit, process capability index and overall equipment effectiveness and also on financial savings. Nicholas and Matthew [7] showed that the application of the DMAIC in lean six sigma approach could lead to improvements including minimise the labor costs, reduce the number of product defect and improve quality of product. Pusporini, Abhary and Luong [8] mentioned two main issues of lean six sigma. Firstly, this methodology focuses on four areas of performance such as cost, quality, time and service and none of current studies of lean six sigma focuses on environmental perspectives. Secondly, the need to integrate environmental aspects into continuous improvement for sustainable development. Based on the current application of lean six sigma methodology at the manufacturing companies, there is no application of integration environmental performance into lean six sigma. Commonly, the environmental evaluation and environmental performance are conducted quite late during the production and are not integrated with any existing development activities. This paper proposes a scheme to put 
environmental performance as an improvement target in the lean six sigma methodology to furnish a sustainable product development.

\section{A REVIEW OF LEAN SIX SIGMA}

Lean six sigma approach is the integration of lean concept (focusessing on eliminating waste) and the six sigma concept (focussing on reducing defect products) to increase customer satisfaction. It focuses on improving quality, decreasing variation and eliminating waste in industry [9]. Lean six sigma is an effective business strategy to decrease costs and achieve a significant improvement in growth and profitability [10]. Most studies on lean six sigma defined it as a continuous improvement methodology that focuses on product and process performance [6], [11], and [14].

Most of the literature on lean six sigma showed that the combination of two methodologies could reinforce each other perfectly and lead to create a powerful approach to improve quality of the product and process and also reduce the time. Lean and six sigma methodologies do not provide potential improvement when applied independently but, together they reinforce each other appropriately [15].

The integration of the lean six sigma concept creates an effective methodology to improve products, process and increase customer satisfaction [11], [14]. The integration of lean six sigma can create a dramatic improvement rather than when lean or six sigma is used separately [16]. This integration can reduce cost, time and improve quality and organisational performance [4], [6]. Lean six sigma will lead to synergies for quality improvement in industry and promote the combination of human and process aspects as a part of process improvement that it will reinforce each other simultaneously [11], [17]. Furthermore, the integration of lean and six sigma principles may lead a significant result by improving the productivity and quality of providing financial services [9].

The application and implementation of lean six sigma methodology will lead to an effective process and satisfaction of customer needs [7]. Furthermore, the industry will gain significant benefit by implementing lean six sigma as a powerful improvement methodology in their business [18].

Generally, two types of common framework are supported by the six sigma concept that will be suitable for the lean six sigma framework too. Firstly, the DMAIC cycle (define, measure, analyse, improve and control) can be used for existing products or processes. Secondly, the DFLS cycle (design for lean sigma) can be applied for the design of new products or processess [3]. The six sigma methodology can be deployed as the DMAIC for process improvement and the DMADV (define, measure, analyse, design and verify) for new product and service development [19]. The usage of DMAIC and DFLS or the DMADV cycle provides a generic framework that can be used as guidance to apply the lean six sigma concept in industry. The DMAIC process can be seen in Fig. 1.

Most recent studies of lean six sigma showed that the DMAIC cycle is a useful framework for lean six sigma implementation [6], [11], [14], and [17]. Every step in DMAIC cycle has a significant correlation with improvement performance and each step needs to be identified clearly.

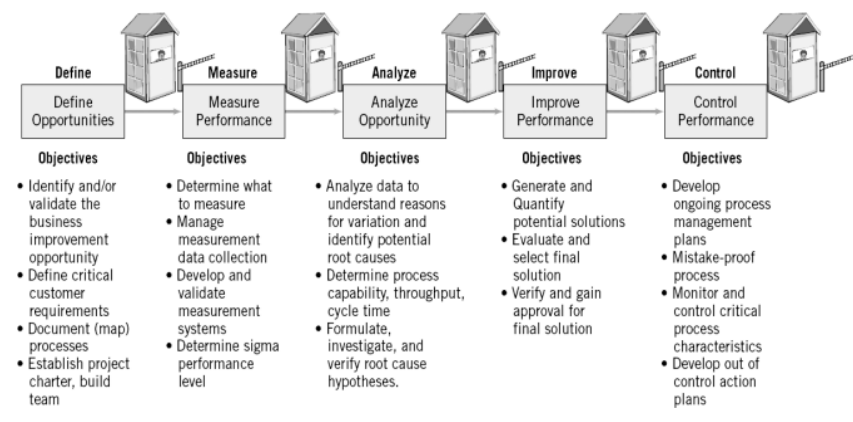

Fig. 1. The DMAIC process [19].

The use of the DMAIC cycle based on the six sigma methodology could systematically improve production quality and reduce cost in the manufacturing shop-floor [20]. The application of the lean six sigma concept by using the DMAIC model could also provide a dramatic improvement in the manufacturing process [5].

\section{DESIGN For SIX SigMA (DFSS)}

In early 1980s, the problem solving algorithm of DMAIC for six sigma initiative was developed. The DMADV is the same as DMAIC algorithm that can be applied to design or redesign of products or processes (Design for Six Sigma or DFSS). Design for six sigma is a systematic approach to design products, processes and services that would meet with the customer expectations. Anthony [21] pointed out that there are some advantages with using DFSS, namely simplifing the configuration of design, eliminating non value activities, and reducing costs.

The process of activities of DFSS consists of four stages: Identify, Design, Optimise and Validate (IDOV). The IDOV is analogous to DMADV methodology. Identify the first stage of IDOV, is equivalent to define and measure stages of DMADV. Moreover, the optimise is equivalent to design of DMADV. The IDOV algorithm is described in the following Sections.

\section{Stage 1: Identify}

This stage is driven by the voice of customer or customer need. The main concern in this stage is how to identify and establish customer requirements. Customer needs would be deployed into Ctitical to Quality (CTQs) factors that have to be considered during the product or process design.

\section{Stage 2: Design}

The main purpose of this stage is to analyse and evaluate the design requirements, key design parameters and their relationship with CTQs.

Stage 3: Optimise

It is to develop the detailed design of products or processes that would meet CTQs and also to optimise the developed design.

Stage 4: Validate

It is to verify the proposed design to ensure that it meets the set of customer requirements identified as CTQs.

\section{Proposed Methodology: IdOV For ENVIRONMENTAL PERFORMANCE MODEL DEVELOPMENT}

This section explains the environmental performance 
model using DFSS. IDOV would be applied to develop the model. The output of this model is described as a level of achievement that have to be achieved related with the environmental performance indicators as input variables.

The flow of IDOV activities can be seen in Fig. 2 .

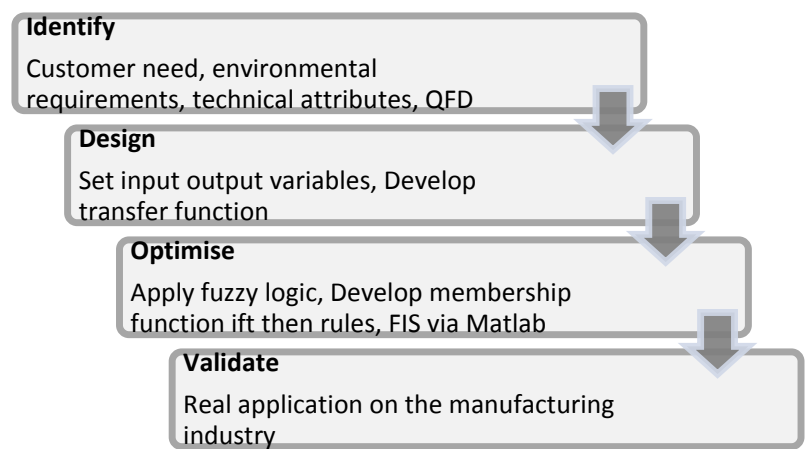

Fig. 2. DFSS flow for environmental performance model using IDOV.

\section{A. Identify}

The product development team consisting of marketing, design, manufacturing, quality control people and experts from the different area of organisation identifies the project scope at this stage. Review of literature, historical data, deep discussion and brainstorming are needed in order to define the main problem. Identifying the scope of project would help the team to specify the main factors for achieving the target.

The team identifies customer and environmental requirements for producing an eco-friendly product. For example, waste reduction, pollution impact reduction, less material usage, easy to transport, easy to process, less energy usage, easy to reuse, easy to smash, easy to sort, safe to incinerate, safe to landfill, harmless to the living environment, safe emission and possible to dispose of at ease. The quality function deployment (QFD) method should be employed to identify the most significant environmental indicators with the aim of transforming customer environmental requirements into characteristics of the products.

\section{B. Design}

This stage is concerned with identifying key input and output variables for the proposed model. The brief review of lean six sigma previously conducted in this paper indicated that the current key performance indicators for lean six sigma project focus on the improvement of quality, cost, time and service. This research includes improvement of environmental performance too. The current key performance indicators for lean six sigma project can be seen in Fig. 3.

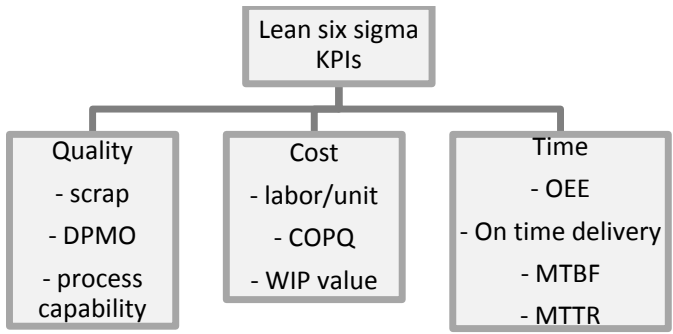

Fig. 3. The current key performance indicators (KPIs) for lean six sigma.

As a continuous improvement methodology, lean six sigma should also address environmental requirements for designing and creating eco friendly products. Fuzzy QFD result from the previous stage and through discussion with experts in the manufacturing industry, the design team can identify the most significant environmental indicators as input variables for the proposed model.

Environmental performance indicators like the amount of energy consumption, the amount of materials to be reprocessed and solid waste are considered and integrated into quality performance indicators for continuous improvement methodology. Pusporini, Abhary and Luong [22] proposed environmental performance indicators as key performance indicators in the lean six sigma methodology and pointed out that the integration of these performance would create a new paradigm of lean six sigma methodology. The integration of quality and environmental performance would achieve the overall competitiveness of product.

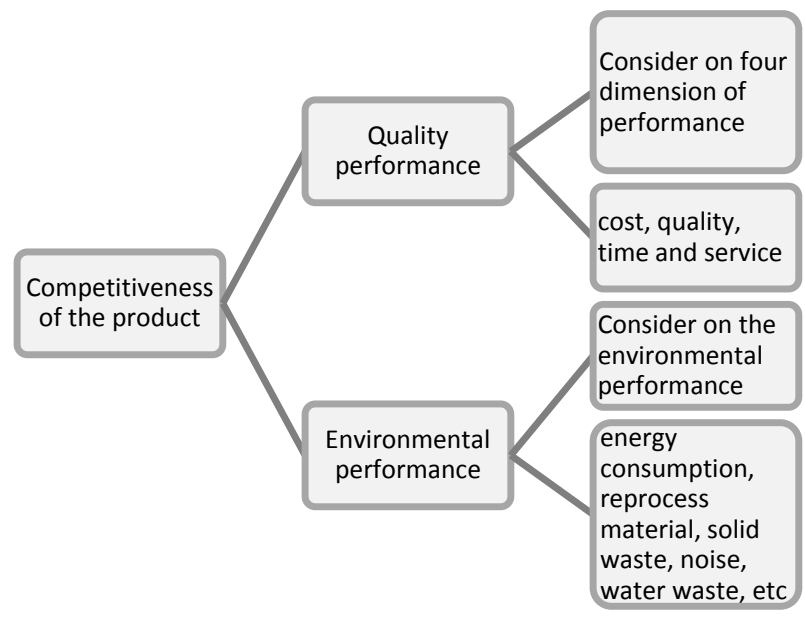

Fig. 4. Key performance indicators for the competitiveness of the product.

The key performance ouput variable for the environmental performance model is described as the environmental performance level. The elemens of output variables in this model include the most significant environmental indicators like energy consumption, reprocess material and solid waste.

\section{Optimise}

The fuzzy logic tool box from MATLAB is applied to develop the environmental performance model. Transfer function of input variables and output variables in fuzzy format can be seen in Fig. 5.

The steps for measuring the environmental performance model using Fuzzy Inference System (FIS) are:

Step 1: The identification of membership function for input and output variables. The identification of membership function for each input variables is based on the expert knowledge from the manufacturing industry. For example: percentage of reprocessed material is set as an input variable for the model. The categories for this measurement are: very high, high, medium, low and very low. Any percentage of reprocessed material around 4 to $6 \%$ is considerd very high and up to $2 \%$ is considered very low. The range between very low and very high are classified as low, medium and high. The categories of reprocessed material and the fuzzy sets for reprocessed material that represent the membership function of input variables can be seen in Fig. 6.

Step 2: Identification of if-then rules 
The identification of the rules will follow the format if (condition $\mathrm{x}$ ) and (condition $\mathrm{y}$ ) then (result $\mathrm{z}$ ) corresponding to the combinations of input conditions. The identification of if-then rules and the upper and lower specification limits for the rules are set according to the expert knowledge of the team at the manufacturing industry. For example: if energy consumption is high and reprocessed material is high and solid waste is high then environmental quality is low. The rule viewer from FIS can be seen in Fig. 7.

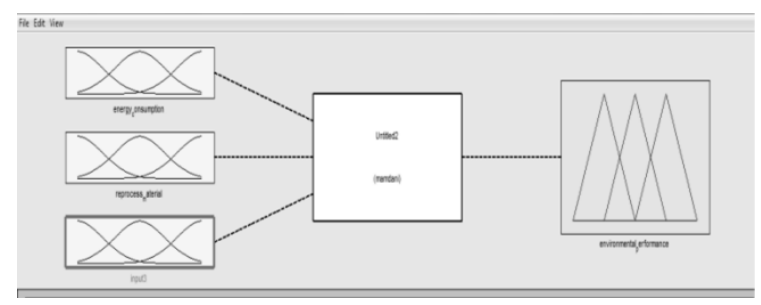

Fig. 5. Transfer function of input output variable in fuzzy format.

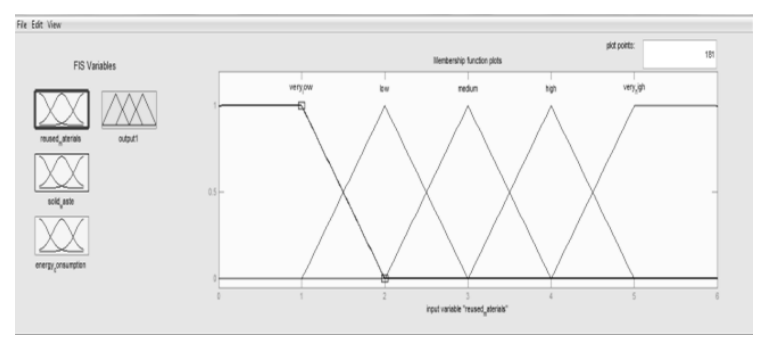

Fig. 6. The membership function for reprocessed material.

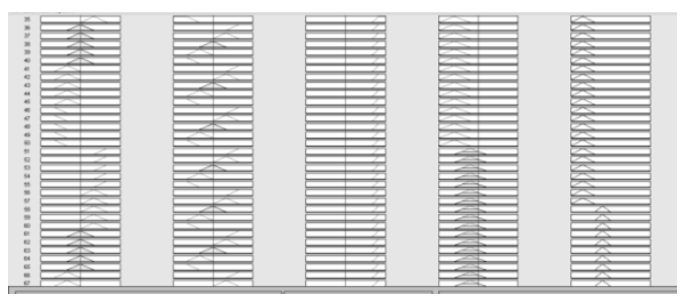

Fig. 7. The rule viewer from the FIS.

The number of these rules is depending on the number of membership function of each input variable. The membership function of each input variable can be modified. However, the modification of the membership function significantly causes the increase or decrease of the number of rules.

Step 3: Fuzzy solutions results

A set of fuzzy solutions is presented using MATLAB fuzzy logic tool box. The upper and lower specification limits of each input variable can be set and then, the output response is calculated as a score that can be translated into linguistic terms. A graphical representation represents the response surface for the output due to two input variables. The output surface from FIS can be seen in Fig. 8.

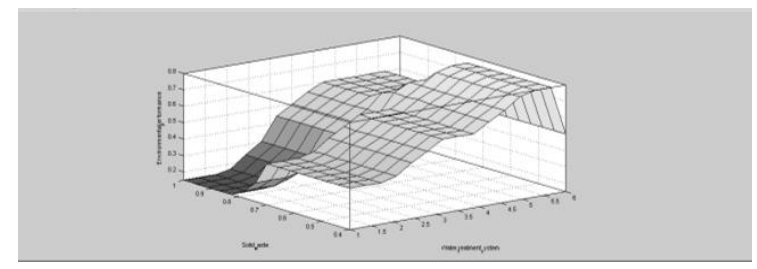

Fig. 8. Output surface from FIS.

\section{Validate}

The model will be analysed and validated to ensure that environmental performance indicators provided would meet the customer and environmental requirements. The developed model should be modified and verified continuously to ensure that the model satisfies the requirements. This includes the application of fuzzy evaluation rules. The flow of IDOV activities facilitates the continuous improvement effort. Then, if the result of the model design did not match with the environmental requirements, then the design team should go back to the identify or design stage. The cycle of IDOV for environmental performance model can be seen in Fig. 9.

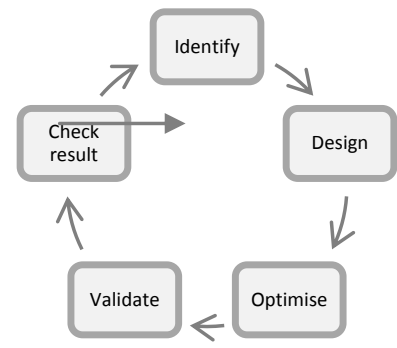

Fig. 9. A cycle of environmental performance model.

\section{CONCLUSION}

This paper proposes the developing of the environmental performance model based on the DFSS methodology. It follows the DFSS phases i.e. identify, design, optimize and validate. The adoption of the DFSS activities and fuzzy logic for developing environmental performance model provides the significant factors of the environmental performance as key performance indicators for lean six sigma methodology. A cycle of the DFSS for developing environmental performance model is possible to modified for the continuous improvement effort.

\section{ACKNOWLEDGMENT}

This work was supported by the Directorate of Higher Education Indonesia (DIKTI) and University of Muhammadiyah Gresik, East Java, Indonesia under Grant Beasiswa Luar Negeri (BLN) DIKTI.

\section{REFERENCES}

[1] D. Tyteca, "On the Measurement of the Environmental Performance of Firms-A Literature Review and a Productive Efficiency Perspective," Journal of Environmental Management, vol. 46, no. 3, pp. 281-308, 1996.

[2] C. Jasch, "Environmental performance evaluation and indicators," Journal of Cleaner Production, vol. 8, no. 1, pp. 79-88, 2000.

[3] F. Aggogeri and M. Mazzola, "Combining six sigma with lean production to increase the performance level of a manufacturing system," in Proc. ASME International Mechanical Engineering Congress and Exposition 2008, IMECE 2008, Boston, Massachusetts, USA.

[4] K. L. Lee and C. C. Wei, "Reducing mold changing time by implementing Lean Six Sigma," Quality and Reliability Engineering International, vol. 26, no. 4, pp. 387-395, 2010.

[5] P. Dario, M. D. Deisell, and G. Howard, "A lean six sigma case study: An application of the "5s" techniques," Journal of Advances in Management Research, vol. 5, no. 1, pp. 63, 2008.

[6] M. Kumar et al., "Implementing the lean sigma framework in an Indian SME: A case study," Production Planning and Control, vol. 17, no. 4, pp. 407-423, 2006 
[7] R. Nicholas and F. Matthew, "Process improvement for printing operations through the DMAIC Lean Six Sigma approach," International Journal of Lean Six Sigma, vol. 1, no. 2, pp. 119, 2010.

[8] P. Pusporini, K. Abhary, and L. Luong, "Introducing environmental aspects into lean six sigma concept for sustainable product development: A literature survey," in Proc. the 12th International Conference on QiR (Quality in Research), 4-7 July 2011. Bali, Indonesia.

[9] S. Furterer, and A. K. Elshennawy, "Implementation of TQM and lean six sigma tools in local government: A framework and a case study," Total Quality Management and Business Excellence, vol. 16, no. 10, pp. 1179-1191, 2005

[10] K. Jeyaraman and T. L. Kee, "A conceptual framework for critical success factors of lean Six Sigma," International Journal of Lean Six Sigma, vol. 1, no. 3, pp. 191, 2010.

[11] C. T. Su, T. L. Chiang, and C. M. Chang, "Improving service quality by capitalising on an integrated lean six sigma methodology," International Journal Six Sigma and Competitive Advantage, vol. 2, no. 1, pp. 1-22, 2006.

[12] T. Andrew, B. Richard, and C. O. Chiamaka, "Applying lean six sigma in a small engineering company - a model for change," Journal of Manufacturing Technology Management, vol. 20, no. 1, pp. 113, 2009.

[13] K. D. Henk et al., "Generic lean six sigma project definitions in publishing," International Journal of Lean Six Sigma, vol. 1, no. 1, pp. 39, 2010.

[14] S. Souraj, R. Abdur, and A. C. Juan, "The integration of six sigma and lean management," International Journal of Lean Six Sigma, vol. 1, no. 3, pp. 249, 2010.

[15] M. P. J. Pepper and T. A. Spedding, "The evolution of lean six sigma," International Journal of Quality and Reliability Management, vol. 27, no. 2 , pp. $138-155,2010$.

[16] E. A. Cudney, M. Mehta, and R. Monroe, "Combining lean and six sigma for optimal result," in Proc. the SME Summit and Annual Meeting, 2006: Los Angeles, California.

[17] R. D. Snee, "Lean six sigma-getting better all the time," International Journal of Lean Six Sigma, vol. 1, no. 1, pp. 9-29, 2010.

[18] W. H. Roger and M. G. Martha, "Lean six sigma, creativity, and innovation," International Journal of Lean Six Sigma, vol. 1, no. 1, pp. $30,2010$.

[19] D. C. Montgomery and W. H. Woodall, "An overview of six sigma," International Statistical Review, vol. 76, no. 3, pp. 329-346, 2008

[20] K. Sameer and S. Michael, "Using DMAIC six sigma to systematically improve shopfloor production quality and costs," International Journal of Productivity and Performance Management, vol. 58, no. 3, pp. 254, 2009.

[21] J. Antony, "Design for six sigma: a breakthrough business improvement strategy for achieving competitive advantage," Work Study, vol. 51, no. 1, pp. 6-8, 2002.

[22] P. Pusporini, K. Abhary, and L. Luong, "Environmental performance as key performance indicators in the lean six-sigma methodology," Advanced Materials Research, vol. 488-489, pp. 1082-1086, 2012.

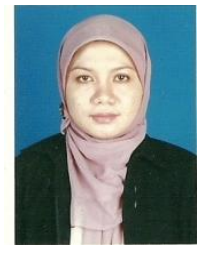

Pregiwati Pusporini is a Ph.D. student at the School of Advanced Manufacturing and Mechanical Engineering, University of South Australia and Lecturer at Department of Industrial Engineering, University of Muhammadiyah Gresik, East Java, Indonesia. She got Indonesian government scholarship for doing her Ph.D. She graduated Bachelor of Engineering in Industrial Engineering from ITN, Malang, East Java, Indonesia and Master of Engineering in Industrial Engineering from ITS Surabaya, East Java, Indonesia. Her research interests in Quality, Six Sigma, Lean, Lean Six Sigma and QFD.

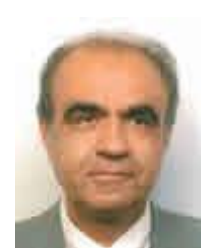

Kazem Abhary is a professor in Sustainable Mech and Manufacturing Design, at School of Advanced Manufacturing and Mechanical Engineering, University of South Australia. He holds B Engineering and M.Eng in Mechanical Engineering from Tehran University, M. Eng. (by research) and Ph.D. in Mechanical Engineering from University of Manchester, Institute of Science and Technology. He is a member of American Society of Mechanical Engineers (ASME), American Society for Engineering Education (ASEE), Australian Association for Engineering Education (AAEE), International Society for Computational Engineering and Sciences. He has an extensive list of publications including numerous international journal and conference papers, two handbook chapters, seven book chapters, four books and a bi-lingual Mechanical Engineering Lexicon, and also published a number of non technical articles on social and literary issues. He is on the editorial board of three International Engineering Journals. His research interests in Design for Manufacture, Assembly and Disassembly, Intelligent Design for Automation, Green (sustainable) Mechanical and Manufacturing Design, Design of Machinery and Vibrations, Computer Aided Design of Mechanical System, Mechanical Structures and Pipelines.

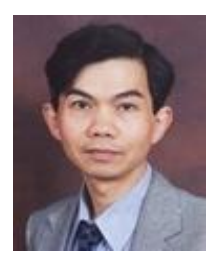

Lee Luong is a professor of manufacturing engineering at the School of Advanced Manufacturing and Mechanical Engineering, University of South Australia. He graduated B. Eng. (Hons), Ph.D. from Monash. He has had extensive experience in teaching, research and academic development within the tertiary sector as well as with industry. Prior to joining the University of South Australia, he worked for more than ten years outside the academic environment, including the mining industry, commonwealth Scientific and Industrial Research Organisation (CSIRO), and Defence Science and Technology Organisation (DSTO). He has an extensive list of publications in international journals and conferences with ten book chapters, forty five journal articles and more than one hundred refereed papers in international conferences. He was The Asia Pacific Editor of the International Journal of Robotics and Computer Integrated Manufacturing for five years and currently on its Editorial Board. His research interests is in the areas of Logistics and Supply Chain Management (Distribution Network Design, Design for Recyclability and Product Upgrade, Close-loop Supply Chain, LCA and Environmental Impact Assessment), and Cellular and Flexible Manufacturing Systems. 